\title{
Attentiveness of Guarding Dogs for Reducing Predation on Domestic Sheep
}

\author{
RAY COPPINGER, JAY LORENZ, JOHN GLENDINNING, AND PETER PINARDI
}

\begin{abstract}
Dogs used to protect domestic sheep from predators are expected to be attentive to the animals they guard. However, $40 \%$ of the sheep producers cooperating in our experimental program to assess the potential of Old World dogs to deter predation in the United States have expressed dissatisfaction with their dog's attentiveness. In contrast, European shepherds appear satisfied with their dogs. In order to find the causes of this apparent difference, a series of measured observations was made in Italy, and data on 4 different strains of imported guarding dogs working in the U.S. were analyzed. The results indicate that the 4 strains are significantly different in attentiveness, although overall it was remarkably similar to the actual attentiveness of Italian dogs. The attentiveness of livestock guarding dogs can be maximized for U.S. sheep producers by (1) selecting strains for superior attentive behavior and (2) adjusting management systems slightly to take advantage of the dogs' capabilities.
\end{abstract}

Protecting sheep (Ovis aries) from predatory canids with another type of canid is the method of choice in parts of Europe but until recently has been practically unknown in the United States. A few individual sheep producers in the U.S. have been using guarding dogs (Canis familiaris) of European ancestry, but until the mid-seventies no studies had tested the effectiveness of livestock guarding dogs with a view toward promoting a successful technique to the U.S. sheep industry. Initial research by various investigators showed promising results (Coppinger and Coppinger 1981; Linhart et al. 1979; Green and Woodruff 1980, 1982), and ranchers from several areas reportcd significant relief from predation.

In order to analyze the effectiveness of this novel technique, a hypothetical model was proposed for an effective canine guardian (Coppinger and Coppinger 1980a). The guardian must exhibit 3 basic behaviors: being trustworthy, attentive, and protective toward sheep. In practice, these behaviors overlap and are not discrete. For example, a dog might be trustworthy because it is totally inattentive or untrustworthy because it is disruptively attentive. Or it may be unprotective, not because of lack of aggression toward potential predators but because of inattentiveness toward the sheep. Adequate protection for the producer, however, can be achieved only if a minimum standard in all 3 behaviors is maintained by the dog.

\footnotetext{
The authors are profess or of biology, School of Natural Science, Hampshire College, Amherst MA 01002; research associate (Lorenz), Livestock Dog Project, and research assistants, Livestock Dog Project, New England Farm Center, Hampshire College.

This study was sponsored primarily by grants from the Rockefeller Brothers Fund and USDA \#59-2259-0-2-1 19-0 to Dr. Coppinger at Hampshire College. Thanks are due to Paolo Breber who introduced us to the ltalian field sites and to the sheepherders and their dogs, and explained our project to members of the Italian Forestry Service. Luigi Potena and his field officers provided housing and guidance in the Foresta Demaniale, and Dr. Bernardo Di Cesare and his officers were guides in the Monti della Laga. Mary Walton translated for us during the Demaniale visit. Quinn and Marilyn Harned supported the acquisition of the Anatolian Shepherd Dogs. Fernando Cinelli and the Grant McCargo family provided barkless environments for data transcription and report writing. Michael Sutherland of the Statistical Consulting Center at the University of Massachusetts assisted with analysis of the data. Lynn Miller and Lorna Coppinger lent editorial expertise.

Manuscript received Nov. 29, 1982.
}

This behavioral model has been useful for analyses of successes and failures of dogs and is now the basis for data collection as we attempt to isolate causes of good guarding ability or a breakdown or lack of that ability. We will address trustworthiness and protectiveness in future papers. In this paper, we present results obtained in a series of studies and experiments on attentiveness. An attentive dog is one that pays attention to and follows the sheep. Attentiveness implies a social bond between dog and sheep which results in the dog constantly maintaining contact with the flock.

Studies on livestock guarding dogs contain several implicit assumptions, most importantly that the behavior of the dogs toward sheep and predators is in part genetic. Most investigators report on dogs with traditional guarding heritages (Linhart et al. 1979, Coppinger and Coppinger 1980b, Green and Woodruff 1980 ), although the work of Black (1981) with Navajo dogs led to his conclusion that almost any breed of dog will do if raised and trained in the proper environment.

The extent to which successful performance of a livestock guarding dog is based on a genetic predisposition and/or training is beginning to receive experimental verification. Arons (1981), testing a time-honored technique reportedly held in value by some Old World shepherds, and indeed noted by Darwin (1972 [1839]), suckled pups on ewes. That stage of development may not be a critical period for socialization, and in fact the suckled pups showed no greater attentiveness to sheep than did normally raised pups. In addition, Green and Woodruff (1980) indicated that Great Pyrenees and Komondors first introduced to sheep at ages greater than 6 months were sometimes successful, which implies either a predisposition for flock guarding or an extended critical period of socialization.

Our interviews with shepherds in Italy, Turkey, and Yugoslavia suggested that nearly $100 \%$ of their dogs are attentive, that is, the dogs are always near the flock and are paying enough attention to it so that they know when something goes wrong. Data from the experimental working dogs we have placed on U.S. farms, however, show that of those dogs judged to be trustworthy with sheep, only slightly better than half are attentive. Since the major inhibition of attentiveness to sheep among American dogs seems to be their attachment to people, a series of observations was designed to test whether sheepdogs working in Italy were focused on the sheep or on the shepherds.

We returned to Italy to determine if, or how, the attentiveness of American guarding dogs differs from that of their Italian counterparts. We assumed that the genetic composition of the strains of dogs we imported in 1977 is similar to the many strains of Maremmas at work in the Abruzzi Mountains where some of our dogs originated a generation ago. Furthermore, since wolves (Canis lupus) prey upon sheep in the Abruzzi Mountains (Boitani 1982), we assumed that shepherds would still be selecting dogs that could protect the flocks. Any differences we measured would probably be due to the working environment and would give us insight into methods for improving livestock guarding dogs for work on U.S. sheep ranges. 


\section{Methods and Materials}

\section{Dogs in the United States}

U.S. dogs in this study were progeny of dogs imported from Italy (Maremma), Turkey (Anatolian Shepherd), and Yugoslavia (Shar Planinetz). They were all purchased for the project by the senior author in situ, with the exception of 8 Anatolian Shepherds donated by members of the Anatolian Shepherd Dog Club of America. Dogs acquired were from working stock or the immediate offspring of working parents. The Maremma purebred puppies were the product of a single sire, while the Shar Planinetz were descended from 2 unrelated sires and 3 sisters. Therefore, the term "strain" is substituted for "breed" in order to give a truer representation of results. The limited sample size of the parental generation does not allow a determination of any between-breed differences.

Pups were raised normally by their mothers for at least 8 weeks at the Hampshire College or the senior author's kennel, always with sheep nearby. After weaning, 200 pups were placed with 139 sheep producers throughout the United States. The producers were a self-selected group who expressed an interest in cooperating, had 20 or more sheep, commercial intent, and were willing to answer an annual questionnaire. The pups were delivered randomly, with little choice allowed as to breed or sex. Placements began in September, 1978, and were continuing at the time of data collection.

Dogs were placed in a variety of conditions, with flocks of 2 dozen sheep which grazed in fenced pasture near the barn, with larger flocks grazing in pastures of several dozen acres, with bands of a thousand or more sheep grazing over unfenced range or fenced range of several hundred acres (Table 1). In the U.S., continuous supervision of sheep is typically minimal, except on summer mountain pastures where a mounted shepherd is usually in attendance. On smaller farms and on well-managed range operations, sheep are housed or gathered at night. However, it is not unusual in the U.S. for some flocks to be unattended from one day to the next.

Farmer/cooperators were given written and oral information on how to manage a guardian dog and were asked to contact us with questions or problems as they arose. In turn, we explained the 3 basic behaviors and what to look for to ensure that each behavior was being properly expressed. In December, 1981, questionnaires for the 200 dogs were sent to the cooperators for their observations during the calendar year. The form contained questions on sheep

Table 1. U.S. cooperator rating of dogs' attentiveness in different management systems, 1981.

\begin{tabular}{lccc}
\hline \hline & $\begin{array}{c}\text { Excellent } \\
\text { or good (\%) }\end{array}$ & $\begin{array}{c}\text { Fair } \\
\text { or poor (\%) }\end{array}$ & $\begin{array}{c}\text { Total number } \\
\text { reported }^{\mathrm{a}}\end{array}$ \\
\hline $\begin{array}{l}\text { Type of operation } \\
\text { Range }\end{array}$ & 62 & 38 & 13 \\
$\quad \begin{array}{l}\text { Fenced } \\
\text { Mixed }\end{array}$ & 61 & 39 & 72 \\
$\quad$ Total & 40 & 60 & $\frac{15}{100}$ \\
Number of sheep guarded & & & \\
0-100 & 55 & 45 & 40 \\
100-1000 & 61 & 39 & 46 \\
l000+ & 63 & 38 & 16 \\
$\quad$ Total & & & 102 \\
Behavior of sheep & & & \\
Flock & 59 & 35 & 16 \\
Loose flock & 58 & 38 & 66 \\
Scittered flock & 45 & 50 & 19 \\
$\quad$ Total & & & 101 \\
Overall attentiveness & 59 & 41 & 102 \\
\hline
\end{tabular}

"The number changes between categories because some individuals did not answer all the questions. management systems, each dog's health and behavior, frequency of predation before and after the dog's arrival, and a checklist for rating each dog's performance. Spot checks on accuracy of responses were made by Coppinger or Lorenz, who visited some of the sites where the dogs worked. For this paper, only the responses for attentiveness were used. Also only those U.S. dogs that were at least a year old $(n=110)$ at the time the questionnaire was sent were selected from the responses.

\section{Dogs in Italy}

Italian shepherd dogs (in Italian, Pastore MaremmanoAbruzzese) were observed in 3 areas of the central Appenine Mountains during June and July, 1982. The areas were chosen because of the numbers of dogs working there, and the similarity of the environment to that of U.S. intermountain ranges (Taylor et al. 1979). Sheep are trucked in for spring and summer grazing. We were introduced to the farmers and their shepherds by Paolo Breber, a native and local authority on the use of livestock guardings dogs in Italy, and interviewed them using the format of the U.S. questionnaire.

The population of sheep and dogs for 2 areas was estimated in 28 sheep camps and crosschecked with the farmers. Grazing in this part of Italy commenced after the morning milking and cheese processing, from about 10 a.m., and lasted until about 4 p.m. Sheep were guided over the grazing allotment by the ever-present shepherd. In the late afternoon the sheep were milked again, put into netting enclosures, and sheep and dogs were left for the night.

In the Monti della Laga the sheep were grazed in the forest. These flocks were usually unattended by the shepherd, but the dogs followed them closely. The dogs were actually performing very much like dogs are expected to in the U.S.: being trustwothy, attentive, and protective without a shepherd present. Sheep were released and directed toward the grazing areas after the morning milking, left, and gathered again in the late afternoon for the evening milking. We could not do a formal study in this area because both dogs and sheep were for the most part invisible among the trees, and the shepherds could give us no information as to the proportion of successful dogs.

In the Gran Sasso we estimated a total of 5,000 sheep and 50 dogs, or about 1 dog per 100 sheep. Sheep were grazed in flocks of about 300 with one shepherd and anywhere from 0 to 5 dogs per flock. Daily counts fluctuated slightly, but on June 28 we counted 37 dogs attending the various flocks and 7 adult dogs (16\%) remaining in 18 camps. Attentive dogs were reasonably tenacious to a particular flock or shepherd on a daily basis although there was some switching of flocks by some dogs.

In the Foresta Demaniale there were about 3,000 sheep and 35 dogs, with 5 dogs remaining in camp during the grazing period. Again, flock size averaged 300 with 1 shepherd and 1 to $5 \mathrm{dogs}$. One operation had 3 dogs that were inattentive and some dogs that switched flocks during the day, complicating data collection. However, sheep and dog management in both areas was similar, and interviews with shepherds confirmed our estimates of the number of dogs.

Three types of observational data were obtained to test the attentiveness of each dog to sheep or to shepherd, all based on the locations of the dogs relative to sheep or shepherd: proximity, orientation, and sidedness (on which side of the flock was the dog relative to the shepherd). Each dog was observed for 4 continuous hours when shepherd, sheep, and dog were out at pasture together. Any general inattentiveness of dogs was investigated by driving to the camps during the day when the sheep were out grazing and searching for dogs that were unattached to the flock. Recording of information was done on portable tape recorders, with standarized data transcribed at the end of each day.

The first observations were made on the proximity of the dog to both shepherd and sheep, and the length of time it spent at that location. For a movement to qualify as a separate observation, the dog had to take a minimum of 5 steps and stop for at least 15 seconds. For the analysis, average distances of a dog from the 
shepherd and from the sheep were computed for the data for each 4-hour period as follows:

$\begin{array}{ll}\text { average distance to shepherd (column): } & \sum_{j=1}^{4} \mathrm{jf}_{+j} / \mathrm{N} \\ \text { average distance to sheep (row): } & \sum_{\mathrm{i}=1}^{4} \text { if }_{\mathrm{i}} / \mathrm{N}\end{array}$

where $\mathrm{j}=$ column dog is in

$i=$ row dog is in

$f=$ frequency of appearances of $\operatorname{dog}$ in box

$\mathbf{N}=$ total number of observations per dog

Both distances were entered in Figure 2 in the appropriate column or row. Dogs which were sheep-attentive were predicted to have low row scores, while those following the shepherd would have low column scores.

The second set of observations was made on each dog's orientation to shepherd or sheep. Often, for example, a resting dog would become alert and follow, when the shepherd started to move, or might follow the sheep even though the shepherd was inactive. When a dog moved and then stopped, the observer recorded an " $A$ " if the dog was closing the distance between itself and the shepherd, or a "B" if it was approaching the sheep. If the observer could not tell or if the movement was not applicable (i.e., the dog chased a rabbit, or the dog, sheep and shepherd were moving single file up a trail), he recorded a " $\mathrm{C}$." The dog's score was given as a percent difference in the total number of $A$ 's and $B$ 's: A - B.

\section{$\overline{\mathbf{A}+\mathbf{B}}$}

Dogs which were attentive to sheep would tend to have high

negative scores since they would be closing the distance between themselves and the sheep, irrespective of the shepherd.

The third set of observations were made on which side of the flock the dog stopped relative to the shepherd. A visual line was drawn through the middle of the flock of sheep parallel to the movement of the sheep, and each time the dog moved and then stopped it was given a plus $(+)$ if it stopped on the same side of the line as the shepherd, or a minus $(-)$ if on the opposite side. If the movement was obscure or not applicable, a zero $(0)$ was recorded. Again, a dog's score was determined as the percent difference in the total number of pluses and minuses recorded: $\frac{(+)-(-)}{(+)+(-)}$ Data for sidedness would place a sheep-attentive dog randomly with respect to the shepherd and thus result in a low score.

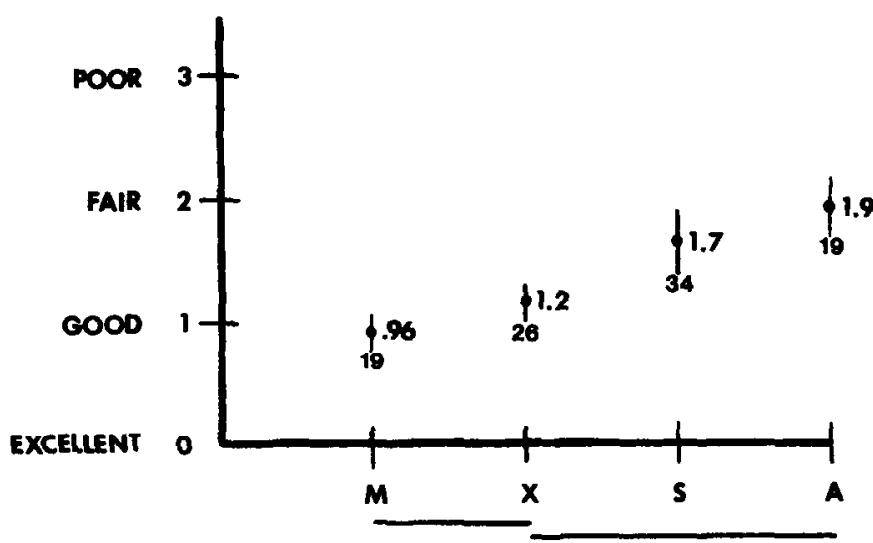

Fig. 1. U.S. cooperator rating of attentiveness of 98 adult dogs, by strain. Average scores are presented $\pm S$.E. (vertical lines). Sample sizes are presented beneath averages. ANOVA, $<<.01$. Duncan multiple range tests, $p<.01$, showing homogeneous subsets, are indicated. $M=$ Maremma; $X=$ Crossbred; $S=$ Shar Planinetz; $A=$ Anatolian.
Table 2. U.S. cooperator rating of attentive dogs from 4 genetic strains, 1981. ANOVA, $p<.01$.

\begin{tabular}{lccc}
\hline Strain & $\begin{array}{c}\text { Excellent } \\
\text { or good }(\%)\end{array}$ & $\begin{array}{c}\text { Fair or } \\
\text { poor }(\%)\end{array}$ & $\begin{array}{c}\text { Total number } \\
\text { reported }\end{array}$ \\
\hline Maremma & 81 & 19 & 26 \\
Crossbred & 68 & 32 & 34 \\
Shar Planinetz & 42 & 58 & 19 \\
Anatolian & 37 & 63 & 19 \\
\hline
\end{tabular}

\section{Results}

\section{Dogs in the United States}

The responses of American sheep producers were analyzed separately according to their type of operation, number of sheep, and flocking behavior of sheep (Table 1). Overall, 59\% of their dogs rated excellent or good in attentiveness. Note that the percentages are fairly uniform except for dogs switched between open range and fenced pasture, in the excellent/good column.

Table 2 and Figure 1 give the percentages of attentiveness for four genetic strains of dog. Differences in overall attentiveness between strains is significant at the .01 level. The Duncan multiple range test shows that the Maremma and Crossbred strains are not significantly different from each other in attentiveness, and neither are the Crossbred, Shar Plainetz and Anatolian subset significantly different from each other. The Maremma and Crossbred subset, however, are significantly more attentive than the Crossbred, Shar Planinetz, and Anatolian subset. The overlap of the Crossbred with each subset is not surprising, since this strain is mostly Maremma X Shar Planinetz crossbreedings.

\section{Dogs in Italy}

The scores for attentiveness of the dog to sheep or shepherd could be arranged independently for each set of observations (proximity, orientation, or sidedness), based on prediction. Since orientation and sidedness scores are continuous $(+1.0$ to -1.0$)$, separation into discrete categories is somewhat arbitrary. Therefore, the data for these two sets of observations are arranged according to the score the dog received for proximity, to see if there is agreement between these various methods (see Table 3).

Figure 2 gives the average proximity of 33 dogs to shepherds and sheep. Generally it was assumed that dogs whose average location score was above the diagonal in Figure 2 were tending to follow the shepherd, while those below were following the sheep. Of course dogs could be following both so for analytical purposes we

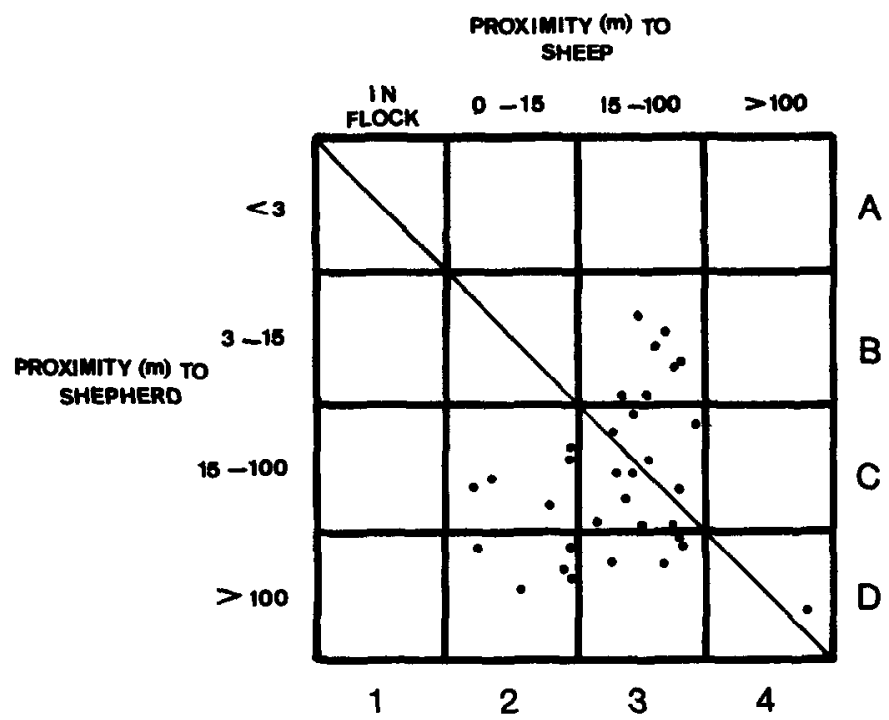

Fig. 2. Average distances to shepherd and sheep of 33 Italian predator control dogs. Letters and numerals on right and bottom axes are discussion references (see text). 
categorized dogs whose average score lay in a diagonal box (A1, B2, C3 or D4) as sheep/shepherd-attentive.

Thirteen dogs $(39 \%)$ were located above the diagonal, which suggests that they were more shepherd-attentive than the 20 dogs $(61 \%)$ below the diagonal which were in closer proximity to the sheep. However, 12 of the 33 dogs (36\%) were in boxes C3 and D4, right on the diagonal, which indicates a possible dual attraction. If we then look at the numbers remaining in boxes above and below the diagonal, we find $14(42 \%)$ following sheep and $7(21 \%)$ following shepherd.

Table 3 gives the average orientation and sidedness scores for the 33 Italian dogs. The orientation prediction here is that dogs strongly oriented toward the shepherd would have high positive scores while those oriented equally to both shepherd and sheep would have low scores, random as to sign.

The orientation data in Table 3 show 9 dogs $(27 \%)$ with positive scores of $50 \%$ or greater indicating that better than 3 out of every 4 times a dog moves it closes the distance between itself and the shepherd. Dual attraction to sheep and shepherd was displayed by 14 dogs ( $42 \%$ ) with 6 positive and 8 negative scores of $49 \%$ or lower. Orientation to sheep appeared in 10 dogs $(30 \%)$ with negative scores above $50 \%$.

The prediction for sidedness is that a dog attentive to sheep would be randomly located as to the side of the flock where the shepherd was. Random location would be indicated by a low score $((+)-(-) \approx 0)$ and a random sign. A preference for the shepherd's side of the flock would be shown by a high score $((+)>(-))$ with a positive value. $A$ dog showing equal attraction for shepherd and sheep would be random as to sidedness when it was following sheep

Table 3. Predictions and scores of orientation and sidedness experiments, listed according to proximity scores.

\begin{tabular}{|c|c|c|c|c|}
\hline \multirow[b]{2}{*}{ Proximity } & \multicolumn{2}{|c|}{ Orientation } & \multicolumn{2}{|c|}{ Sidedness } \\
\hline & $\begin{array}{r}\text { Actual } \\
\text { score }\end{array}$ & Predition $\bar{x}$ & $\begin{array}{r}\text { Actual } \\
\text { score }\end{array}$ & Prediction $\bar{x}$ \\
\hline $\begin{array}{l}\text { Shepherd- } \\
\text { attentive }\end{array}$ & $\begin{array}{r}1.00 \\
1.00 \\
.89 \\
.71 \\
.65 \\
.60 \\
.50\end{array}$ & $(+)$ high +.76 & $\begin{array}{r}1.00 \\
.90 \\
.70 \\
.65 \\
.54 \\
.54 \\
.47\end{array}$ & $(+)$ high +.69 \\
\hline $\begin{array}{l}\text { Shepherd/sheep- } \\
\text { attentive }\end{array}$ & $\begin{array}{r}.60 \\
.50 \\
.44 \\
.26 \\
.22 \\
.20 \\
.09 \\
.06 \\
-.25 \\
-.37 \\
-.78 \\
-1.00\end{array}$ & 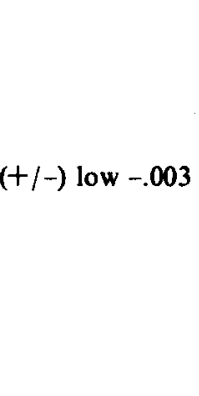 & $\begin{array}{c}1.00 \\
.72 \\
.58 \\
.46 \\
.38 \\
.36 \\
.32 \\
.16 \\
.14 \\
.12 \\
.06 \\
-.10\end{array}$ & +) moderate +.35 \\
\hline $\begin{array}{l}\text { Sheep- } \\
\text { attentive }\end{array}$ & $\begin{array}{r}.02 \\
.00 \\
-.06 \\
-.22 \\
-.25 \\
-.28 \\
-.56 \\
-.60 \\
-.67 \\
-.73 \\
-.83 \\
-.85 \\
-.88 \\
-1.00\end{array}$ & $(+)$ high -.49 & $\begin{array}{r}.78 \\
.74 \\
.66 \\
.56 \\
.32 \\
.30 \\
.22 \\
.20 \\
-.06 \\
-.12 \\
-.20 \\
-.25 \\
-.36 \\
-.42\end{array}$ & $(+/-)$ low +.17 \\
\hline
\end{tabular}

but nonrandom when following the shepherd. Thus $(+)$ would $b$ greater than (-), but a more moderate score would be predicted

In the experiment for sidedness, 7 dogs (23\%) scored moderat (.33 to .66) and positive, and 14 dogs ( $45 \%)$ scored low (0 to .32) c which 5 were negative. Two dogs with moderate negative score $(-.42$ and - .36) were placed in the sheep-sided group even thoug their scores were higher than predicted. In both cases these dog appeared to be avoiding the shepherds and shepherd-sided dogs

Although there is fair agreement within each category, individ ual dogs changed categories within the different sets of observa tions. In several cases it was obvious that there were other factor influencing the dog besides just sheep and shepherd. In one case : shepherd beat a dog which then avoided him, appearing to be : sheep-attentive dog; in other cases there were dominance struggle between dogs which influenced their scores.

\section{Discussion and Conclusion}

Although direct comparisons between the U.S. and Italian dat: cannot be made due to differences in data collection, the higl numbers of observations involved in both sets of data and the minimum of 1 year's practical experience of the cooperating farmers revealed a consistency in the reports and hence impar reliability to the scores.

American sheep producers rated $59 \%$ of their dogs to be attentive to sheep. Between strains of dogs, there was a significant difference $(p<.01)$ in attentiveness ranging from $81 \%$ excellent or good, to $37 \%$ (Table 2 ). We could detect no environmental differences in the way each of these strains was managed, and in fact precautions were taken in the distribution of dogs in order to guard against any biases. It is noteworthy that dogs raised in different management systems (fenced vs. open range) have the same percentages of good/excellent dogs.

Observations of Italian dogs indicated that these dogs behave very much like the ones working in the U.S. However, the Italian management system differs enough from U.S. systems to make even their inattentive dogs valuable as livestock protectors. Managing sheep in the Gran Sasso and Foresta Demaniale involved one 6-hour grazing period per day. The sheep were milked in the morning and accompanied out onto the range by dogs and shepherd. Thirty-seven percent of the dogs in the region either stayed in camp or were following the shepherd and not the sheep; $29 \%$ of the dogs were following both shepherd and sheep. Therefore, only $34 \%$ were truly attentive to the sheep alone, and would no doubt rate an "excellent" in attentiveness from a U.S. sheep producer.

Looking at Figure 2, we find that half the dogs are below the diagonal, and so are sheep-attentive dogs, thus approaching the $59 \%$ good/excellent sheep-attentive dogs in the U.S. The discrepancy between the Italian claim of $100 \%$ attentive dogs and the $50 \%$ we measured is due to the Italian system of managing sheep, which provides a framework that keeps all the dogs on the job for at least part of the day. Shepherd-attentive dogs follow the shepherd and thus attend the sheep during grazing. Dogs in camp are surrounded by sheep for that portion of the day when the sheep are back in camp. Sheep-attentive dogs follow the sheep out for the day and then back in the evening. Thus, dogs of varying ability are useful in their total system.

That this following instinct has a genetic component is suggested by the data on U.S. guarding dogs (Figure 1 and Table 2), and by the similarity between the frequency of ideal performances of Italian and American dogs (Table 2 and Figure 2), even though management on the two continents is quite different. This is not to suggest that there are not environmental influences on the behavior, but simply to point to the fact that in a given area certain dogs are more predisposed to show this behavior, and that the predisposition is probably genetically based. By implementing a program of selective breeding, then, the frequency of attentive dogs could be greatly improved.

In the meantime, dogs with less than adequate attentive behavior could reduce losses to predators on U.S. pastures and ranges if 
producers would adapt their management systems enough to take advantage of the talents their dogs do have. People-oriented dogs must be weaned from people to sheep, or provided with a shepherd. Dogs that spend their time at the barn and not with the sheep must also be taught to stay with the flock. If corrective measures do not work, it may be time to get a different dog, one that better suits an individual's livestock management system.

\section{Literature Cited}

Arons, C. 1981. Raising livestock guarding dogs. Sheep Canada 5(3):5-7. Boitani, L. 1982. Wolf management in intensively used areas of Italy. p. 158-1 72 In: F.H. Harrington and P.C. Paquet, eds. Wolves of the World. Noyes Publications, N.J.

Black, H. 1981. Navajo sheep and goat guarding dogs: a new world solution to the coyote problem. Rangelands 3:235-237.
Coppinger, R., and L. Coppinger. 1980a. Livestock-guarding dogs. Country Journal 7(4):68-77.

Coppinger, L., and R. Coppinger. 1980b. So firm a friendship. Natural History $89(3): 12-26$.

Coppinger, R., and L. Coppinger. 1981. Protecting the flock. Sheep! (July): 14-17.

Darwin, C. 1972[1839]. The Voyage of the Beagle. Bantam Books N.Y.

Green, J.S., and R.A. Woodruff. 1980. Is predator control going to the dogs? Rangelands 2:187-189.

Green, J.S., and R.A. Woodruff. 1982. Livestock guarding dog research at the U.S. sheep experiment station. Sheep Canada 7(1):6-7.

Linhart, S.B., R.T. Sterner, T.C. Carrigan, and D.R. Henne. 1979. Komondor guarding dogs reduce sheep losses to coyotes: a preliminary evaluation. J. Range Manage. 32:238-241.

Taylor, R.F., J.P. Workman, and J.E. Brown. 1979. The economics of sheep predation in southwestern Utah. J. Range Manage. 32:317-321.

\section{To increase carrying capacity, improve forage quality and extend the pasture season, plant...}

\section{Perma-Pel Horse Pasture Seed Mix}

A special blend of tender, hardy grasses that are favored by horses and provide good protein forage and inexpensive TDN that saves on hay and grain costs. Grass seeds are selected for plants that grow good sod pastures, to reduce plant damage from trampling by horses with good pasture management. There are no clover seeds in this mix.

\section{Perma-Pel Cattle and Sheep Pasture Seed Mix}

A special blend with grasses, clovers and sub-clovers and other legume seeds to grow pastures that put efficient, economical weight gains on cattle and sheep. Special care is taken in this mix to add plants that reduce the danger of bloat, so long as a balanced grass population is maintained.
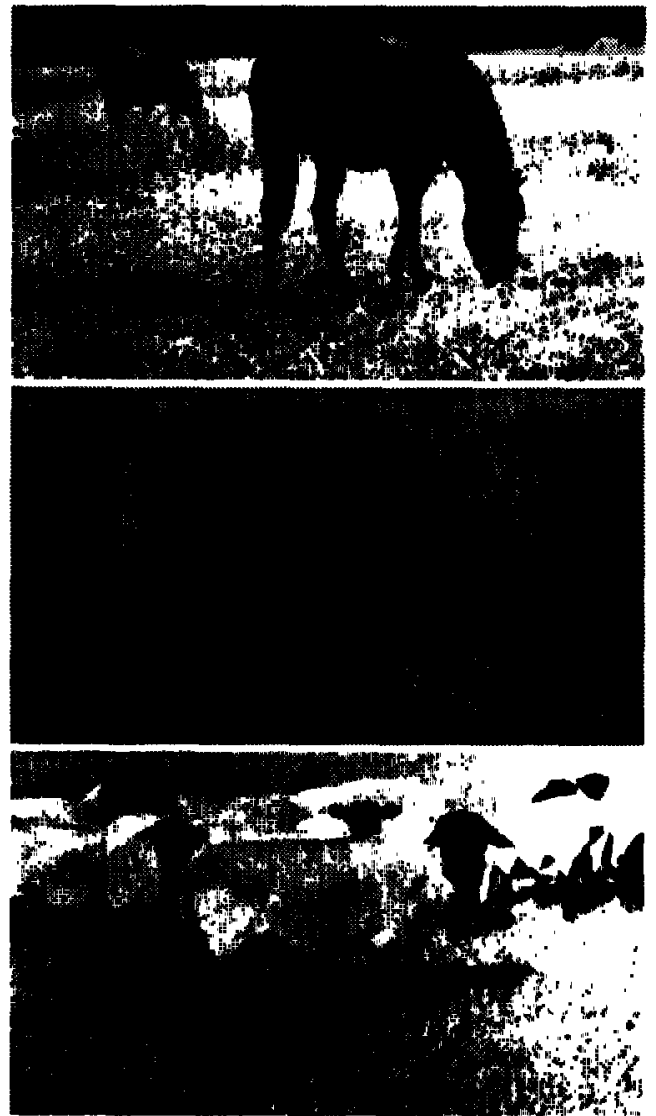

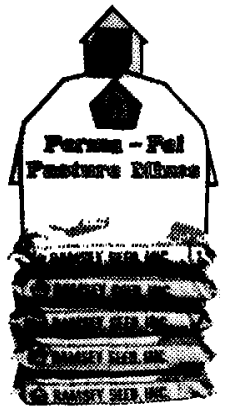

One bag plants one acre.

Perma-Pel Pasture Seed Mixes are conveniently packaged in bags designed for planting one acre. Both grass and legume seeds are coated with additives that enhance the microenvironment of

the soil surrounding the seed and promote a high emergence rate. The extra weight of this coating also anchors the seed to the ground and camouflages the seeds to prevent loss from birds while awaiting germination. All legume seeds are also coated with Rhizo-Kote to innoculate the seed with rhizobia (soil bacteria) to assure proper nitrogen fixation of the legume plants.

Look for this special Perma-Pel Pasture Seed Mix at your local seed dealer.

RAvSET SEBD, ING. P.O. Box 352, Manteca, CA'95336 (209) 823-1721 